\title{
Research Square \\ Clinical and echocardiographic management of patients with Chronic Heart Failure and Type 2 Diabetes Mellitus: the SCODIAC Follow up Study
}

Mariarosaria De Luca

Universita degli Studi di Napoli Federico II

Giorgio Bosso

Associazioni Regionali Cardiologi Ambulatoriali

Antonio Valvano

Associazioni Regionali Cardiologi Ambulatoriali

Vincenzo Guardasole

Universita degli Studi di Napoli Federico II

Amodio Botta

Associazione Medici Diabetologi

Vincenzo Carbone

Associazioni Regionali Cardiologi Ambulatoriali

Giovanni Carella

Associazioni Regionali Cardiologi Ambulatoriali

Andrea Del Buono

Associazione Medici Diabetologi

Giuseppe Di Giovanni

Associazione Medici Diabetologi

Biagio Fimiani

Associazioni Regionali Cardiologi Ambulatoriali

Franco Guarnaccia

Associazioni Regionali Cardiologi Ambulatoriali

Emanuela Lapice

Associazione Medici Diabetologi

Emilia Martedî

Associazione Medici Diabetologi

Giuseppe Memoli

Associazione Medici Diabetologi

Domenica Oliva

Associazione Medici Diabetologi

Geremia Romano 
Associazione Medici Diabetologi

Antonio Cittadini

Universita degli Studi di Napoli Federico II

Giovanni Battista Zito

Associazioni Regionali Cardiologi Ambulatoriali

Ugo Oliviero ( $\square$ ugo.oliviero@unina.it)

University Federico II

\section{Original investigation}

Keywords: Heart Failure, Diabetes, Echocardiography, Ejection Fraction

Posted Date: May 22nd, 2020

DOI: https://doi.org/10.21203/rs.3.rs-27651/v1

License: (c) (i) This work is licensed under a Creative Commons Attribution 4.0 International License. Read Full License 


\section{Abstract \\ Background}

SCODIAC study revealed an increasing use of SGLT2 inhibitors in 123 patients affected with Heart Failure (HF) and Type 2 Diabetes Mellitus (T2DM), referred to Cardiologists and Diabetologists of the pertaining healthcare districts. SCODIAC Follow Up, the second phase of the program, has been carried out to determine diagnostic and therapeutic pathways in a larger group of HF diabetic patients and to verify whether the use of innovative antidiabetic therapies could modify echocardiographic parameters and influence cardiological therapy.

\section{Methods}

406 patients affected with HF and T2DM, referred to Cardiologists and Diabetologists of pertaining healthcare districts in Campania, and followed for at least one year between 2018 and 2019, were enrolled in this retrospective study and divided in Group A, composed of $136 \mathrm{HF}$ diabetic patients with preserved Ejection Fraction (HF-pEF) (> 45\%) and Group B, formed of 270 HF diabetic patients with reduced $\mathrm{EF}(\mathrm{HF}-\mathrm{rEF})(\leq 45 \%)$. All patients had performed periodic clinical evaluations and an echocardiographic exam every 12 months. Anthropometric parameters, HF etiology, co-morbidities, complications and ongoing therapies were collected.

\section{Results}

The clinical and laboratory parameters and the treatments adopted were assessed at beginning and after 12 months of treatment. The antidiabetic therapies resulted modified after one year with a greater use of GLP1 AR, gliptins and SGLT2i. Cardiological therapy resulted also modified with a greater use of ARNI and a reduction of ACE inhibitors and ARBs in HF-rEF patients. At the end of the study echocardiography E velocity, A velocity and E/E' ratio resulted markedly reduced in $25 \mathrm{HF}-\mathrm{pEF}$ patients and in $60 \mathrm{HF}-\mathrm{rEF}$ patients treated with SGLT2i, in respect to both the whole sample of subjects at beginning and the other diabetic patients, while LAVi resulted reduced only in HF-pEF patients and EF increased only in HF-rEF patients.

\section{Conclusions}

The approach to the patients with HF and T2DM must necessarily take place in the healthcare districts and be multidisciplinary and integrated in order to tailor therapy to the characteristics of the patient. SGLT2i could improve left ventricular function in HF-rEF patients and modify cardiological therapeutic approach, almost in this setting of patients. 


\section{Trial registration:}

The protocol was approved by the University of Naples Federico II Ethics Committee and registered at ClinicalTrial.gov (CT04375943). The principles outlined in the Declaration of Helsinki were followed.

\section{Background}

Heart Failure (HF) represents the first cause of hospitalization among the over $65 \mathrm{~s}$ and cardiovascular death in Italy, with an incidence of 200,000 new cases per year, progressively growing cause the improvement of the natural history of cardiovascular diseases (1). The mortality rate is very high, with a natural history not longer than 4-5 years after diagnosis (2), and the overall economic impact (including in and out-of-hospital) is remarkable. Likewise, Type 2 Diabetes Mellitus (T2DM) is an important public health problem, with prevalence and incidence progressively increasing. The two pathologies often coexist: in the Framingham study the incidence of HF is almost doubled in males and quintupled in females with T2DM (3). Italian data show that about $12 \%$ of patients with T2DM are affected with HF and $30 \%$ of HF patients are diabetic (4), so that it is conceivable that preventive measures, such as control of body weight and blood pressure values, have to be adopted in the management of both HF and diabetic patients. SCODIAC (SCOmpenso cardiaco and DIAbete in Campania) (5) was a retrospective study designed by the Associazioni Regionali Cardiologi Ambulatoriali (ARCA) Campania and the Associazione Medici Diabetologi (AMD) Campania to evaluate diagnostic and therapeutic pathways, appropriateness and effectiveness of a multidisciplinary approach in patients with HF and T2DM. The study revealed a significant reduction in the use of insulin, metformin, sulfonylureas and thiazolidinediones and an increasing use of Sodium-Glucose Co-Transporter 2 inhibitors (SGLT2i) and drugs acting on incretin axis during the time, especially in HF-rEF (Heart Failure with reduced Ejection Fraction) patients. Cardiological therapy also resulted modified after one year: in particular, the prescription of sacubitril-valsartan resulted markedly increased in HF-rEF patients.

SCODIAC Follow Up has been carried out to determine diagnostic and therapeutic pathways in a larger population of HF diabetic patients referred to both Cardiology and Diabetology Centers in Campania and verify whether the use of innovative antidiabetic therapies could modify echocardiographic parameters and influence HF therapy.

\section{Materials And Methods}

A total of 406 patient with HF and T2DM, referred to ARCA Cardiologists from 17 healthcare districts in Campania and to AMD Physicians from 8 Antidiabetic Centers and followed for at least one year between 2018 and 2019, were enrolled: 303 prevalent patients (123 patients previously evaluated in SCODIAC study (5), 180 recruited from ALERT HF Follow Up Study (6)) and 103 incident outpatients recruited during the last year. Inclusion criteria were age at least 65 years, the presence of chronic HF, defined as a stable clinical syndrome with typical symptoms and signs and echocardiographic evidence of cardiac involvement, New York Heart Association (NYHA) class II-III, and a diagnosis of T2DM from at least 
2 years. Exclusion criteria were cardiac surgery performed during the last year; age less than 65 years; significant valvulopathies, malignant neoplasms and advanced chronic kidney disease. The protocol was approved by the University of Naples Federico II Ethics Committee and registered at ClinicalTrial.gov (CT04375943). The principles outlined in the Declaration of Helsinki were followed. The 406 patients were divided in two groups according different values of left ventricular Ejection Fraction (EF): $136 \mathrm{HF}$ diabetic patients with preserved EF (HF-pEF) (>45\%) were assigned to Group A and $270 \mathrm{HF}$ diabetic patients with reduced EF (HF-rEF) ( $\leq 45 \%)$ to Group B. All patients performed periodic evaluations by their own Cardiologists and Diabetologists and an echocardiographic examination at beginning and after one year of treatment. Clinical and laboratory parameters, disease duration, HF etiologies, co-morbidities and complications, number of accesses to the pertaining healthcare district and ongoing therapies were collected. The echocardiographic parameters recorded at the beginning and at the end of the trial were: LV (Left Ventricular) volume at end diastole and end systole, LV mass, relative wall thickness and left atrial volume, LV ejection fraction using Simpson's biplane rule, peak velocity of mitral $E$ and $A$ waves and the E/A ratio, Tissue Doppler Imaging (TDI) diastolic velocities of mitral annulus and the E/E' ratio. A comparison of the echocardiographic parameters registered at baseline and at the end of the study was performed between patients who assumed SGLT2i and patients who not assumed, for each EF group.

\section{Statistical Analysis}

Data related to the beginning of the study and after twelve months were analyzed. Continuous data are expressed as mean \pm standard deviation. Student $t$ test for unpaired values was used to compare the quantitative variables. Bonferroni correction was applied when indicated. Categorical variables were presented as frequencies and percentages and compared using chi-square test with Yates correction. A value of $P<0.05$ was considered statistically significant. Statistical analysis was performed using the SPSS package, version 22 (SPSS Inc., Chicago, IL).

\section{Results}

Clinical characteristics and laboratory data of the study population are summarized in Table 1. The routine laboratory parameters resulted comparable in the two groups. Patients with reduced EF showed the longer duration of HF and had significantly higher Brain Natriuretic Peptide (BNP) values (330 \pm 89 in Group A vs $778 \pm 153$ in Group B, $p<0.05$ ) in respect to patients with HF-pEF.

As regard the causes of $\mathrm{HF}$, a prevalent hypertensive etiology was observed in Group A while an ischemic one and the idiopathic dilated cardiomyopathy resulted prevalent in Group B (Table 2), as well as the most common co-morbidity was hypertension in the Group A and ischemic heart disease in the Group B. Twenty-two HF-pEF and $40 \mathrm{HF}-\mathrm{rEF}$ patients were affected with atrial fibrillation and treated with Direct Oral Anticoagulants. The most frequent complication was diabetic nephropathy (44\% of the whole group of patients, without differences between Group A and Group B), followed by peripheral atherosclerotic disease $(24 \%)$ and diabetic retinopathy $(17 \%)$. 
Table 3 showed clinical characteristics and laboratory data of the study population and of the two study Groups at the beginning and at the end of the study. No significant differences were detected between the two groups of patients. The antidiabetic therapy was assessed at the beginning and at the end of the study (Figures 1). A significant reduction in metformin and a not significant descendent trend in the use of sulfonylureas, glinids, pioglitazone and insulin were observed after 12 months in both groups. Moreover, at the end of the study, a significant larger assumption of Glucagon-like Peptide-1 receptor agonists (GLP1-ra) and SGLT2i was noticed in both the groups of HF diabetic patients.

Similarly, at the end of the study, HF therapy was checked in the two Groups (Figure 2). The use of Angiotensin-converting enzyme inhibitors (ACE-I) and Angiotensin Receptor Blockers (ARB) was almost unvaried in HF-pEF patients, but it resulted significantly decreased in HF-rEF patients, probably cause the increasing prescription of sacubitril/valsartan (from 22.8\% to 89.3\%, $p<0.001$ ). Moreover, the number of patients receiving nitrates resulted increased at the end of the trial, particularly in HF-rEF patients (from $41.1 \%$ to $69.3 \%, p<0.05)$.

Table 4 shows the echocardiographic parameters in 136 HF-pEF patients at beginning of the study, and in 25 and 111 among them treated or not with SGLT2 $i$ at the end of the study. No differences were observed between the whole sample of the HF-pEF diabetic patients at beginning and 111 patients without SGLT2i therapy at the end of the study. LAVi, E velocity, A velocity and E/E' ratio, conversely, resulted markedly reduced in patients treated with SGLT2i at the end of the study, in respect to the whole group of subjects at beginning and to HF-pEF patients treated with different antidiabetic therapies.

The echocardiographic parameters of $270 \mathrm{HF}-\mathrm{rEF}$ patients at the beginning, and 60 and 210 patients treated or not with SGLT2i at the end of the study are summarized in Table 5. No differences were observed between the HF-rEF diabetic patients at beginning and the 210 patients without SGLT2i therapy at the end of the study. LV-EDVi, LV-ESVi, E and $A$ velocity and E/E' ratio resulted markedly reduced in 60 patients treated with SGLT2i at the end of the study, in respect to the whole group of subjects at beginning and to HF-rEF patients treated with other antidiabetic therapies after 12 months; at the same time EF resulted increased.

\section{Discussion}

T2DM is a well-known risk factor for HF at different etiologies. In turn, HF worsens life quality and complicates management of diabetic patients, with a significant increasing of the sanitary costs. Therefore, it's necessary a personalized treatment with positive impact on both pathologies, according to the age, the co-morbidities and the natural history of the prevalent disease. This retrospective study was designed to detect diagnostic and therapeutic pathways in two groups of HF diabetic patients with different values of EF and to verify whether the use of innovative antidiabetic therapies could change clinical, laboratory and echocardiographic parameters and modify cardiological therapy adopted. Clinical and laboratory parameters were comparable in the two groups at the beginning and at the end of the study. However, HF-rEF patients had a longer disease duration, higher BNP values, and more often were 
affected with ischemic heart disease. At the end of the trial, the antidiabetic therapy resulted markedly modified: the use of metformin slightly decreased and the use of SGLT2i and GLP-1 RA increased in both groups, less in HF-pEF patients. These results are consistent with current scientific evidence about the relationship between antidiabetic treatments and heart failure: while the safety of metformin is well demonstrated in HF patient (7), data are inconsistent regarding use of sulfonylureas and glinids $(8,9)$, the thiazolidinediones are contraindicated (10) and conflicting results have been reported regarding Dipeptidyl peptidase-4 inhibitors (DPP4i) (11-14). Therefore, GLP1 receptor agonists have potential favorable effects on the natural history of heart failure $(15,16)$, and SGLT2 inhibitors are indicated in the treatment of T2DM cause the beneficial effects of the drugs on cardiovascular outcomes (17-22). Recently, the favorable effects of SGLT2i on cardiovascular outcomes have been confirmed in HF patients even in absence of diabetes (23). These results suggest that SGLT2i could exert their action through an amelioration of the cardiac function, but the relative pathogenesis is still incompletely understood, conceivably related to an improvement of LV mass index and diastolic function (24). In the present study, all patients performed echocardiography at the beginning and after one year. We compared echocardiographic data between HF-pEF diabetic patients at beginning and HF-pEF patients not treated with SGLT2i after 12 months. Data didn't show any significant difference. On the other hand, comparing HF-pEF patients treated with SGLT2i in respect to other diabetic patients differently treated after 12 months, LAVi, E velocity, A velocity and E/E' ratio resulted reduced, suggesting that SGLT2i could improve diastolic function in diabetic HF-pEF patients. At the same way, echocardiographic parameters of not SGLT2i treated HF-rEF patients at the beginning and 12 month later didn't show any significant difference. Conversely, an improvement of systolic function was observed after 12 months in SGLT2i treated HF-rEF patients: both LV-EDV and LV-ESV resulted reduced, while the Ejection Fraction slightly increased. According to our knowledge only few clinical studies evaluated changes in LV function and structure in HF patients treated with SGLT2i, and their data are consistent with our results, showing an improvement of cardiac function after a short period of therapy, obtained with mechanisms still unclear and discussed (24-26).

As the antidiabetic therapy, cardiological treatments resulted markedly modified after one-year follow-up. Sacubitril/valsartan intake significantly increased in HF-rEF patients after one year, while the use AceInhibitors and ARBs markedly reduced. In our previous study (27), we observed poor adherence to guidelines-based therapy in class NYHA III HF-rEF patients aged more of 65 years, especially as concern antialdosteronics, anticoagulant therapy in presence of atrial fibrillation, implanted device system. During 3-years follow-up, we observed a reduction of vascular events and a significant increase in adherence to guidelines for all the indicators selected, probably cause the strict follow-up realized by their own Cardiologists in the pertaining Health Districts (28). At the same way, HF diabetic patients included in our study were followed during one year by their own Diabetologists and Cardiologists in the pertaining Healthcare Districts, and this circumstance could explain why none of the HF-rEF diabetic patients treated with SGLT2i introduced in therapy sacubitril-valsartan: the hypotensive and diuretic effects common to both the drugs probably discouraged the referring Cardiologists and Diabetologists to prescribe sacubitril/valsartan on a background of SGLT2i therapy. On the other hand, SGLT2i therapy could have 
improved the general health status and the echocardiographic pattern of treated patients, excluding the introduction of sacubitril/valsartan (24). Scientific evidence on the combined use of the two drugs is currently limited: in DAPA-HF (23), only $11 \%$ of patients were co-prescribed with dapagliflozin and sacubitril-valsartan, with similar cardiovascular outcomes in respect to the patients treated with dapagliflozin and valsartan. So current data suggest that SGLT2i could be strongly indicated in those patients who can't take sacubitril-valsartan for kidney disease or hypotension and HF diabetic patients followed in this study have been treated accordingly.

\section{Conclusion}

The approach to the patients with Heart Failure and Type 2 Diabetes Mellitus must necessarily take place in the healthcare districts, be multidisciplinary and integrated, and involve both Cardiologists and Diabetologists, for tailoring therapy to the characteristics of the patient. In particular, SGLT2i could improve left ventricular function in HF-rEF diabetic patients and modify cardiological therapeutic approach in this setting of patients, even if further studies specifically designed and conducted on a larger sample of HF patients should be carried out to confirm these effects.

Limitations: The data reported in SCODIAC Follow up study have several limitations. Firstly, the study was retrospective, and the groups of the patients enrolled were not matched with a control group. The results obtained, moreover, are not generalizable to other populations affected with HF and diabetes and followed in different clinical settings. Furthermore, the compliance of the patients to the treatments prescribed is not certain: a psychological test to detect the presence of mild cognitive impairments was not available for all patients and periodical evaluations during one year of follow up were not performed. At the same time, the clinical status of the patients enrolled could have been more detailed, even if almost all of the patients referred by themselves to the pertaining healthcare district, showing an acceptable performance status. The echocardiographic data analysis has been only focused on the patients cotreated or not with SGLT2i: it would be of great interest to correlate the echocardiographic parameters with the baseline and the final therapies of all the subgroups of patients in an attempt to identify a potential role of the singular treatment adopted. This was not possible in the current study because of the small dimension of the patient subsets treated with different approaches.

\section{Abbreviations}

ACE-l: Angiotensin-converting enzyme inhibitors; AMD: Associazione Medici Diabetologi; ARB Angiotensin Receptor Blockers; ARCA: Associazioni Regionali Cardiologi Ambulatoriali; BNP: Brain Natriuretic Peptide; DPP4i: Dipeptidyl peptidase-4 inhibitors; EF: Ejection Fraction; GLP1-ra: Glucagon-like Peptide-1 receptor agonists; HF: Heart Failure; HF-pEF: Heart Failure with preserved Ejection Fraction); HF-rEF: Heart Failure with reduced Ejection Fraction; LV: Left Ventricular; NYHA: New York Heart Association; SCODIAC: SCOmpenso cardiaco and DIAbete in Campania; SGLT2i: Sodium-Glucose Co-Transporter 2 inhibitors; TDI: Tissue Doppler Imaging; T2DM: Type 2 Diabetes Mellitus. 


\section{Declarations}

\section{Ethics approval and consent to participate}

The protocol was approved by the University of Naples Federico II Ethics Committee and registered at ClinicalTrial.gov (CT04375943). The principles outlined in the Declaration of Helsinki were followed.

\section{Consent for publication}

Not applicable.

\section{Availability of data and materials}

The datasets used and/or analysed during the current study are available from the corresponding author on reasonable request.

\section{Competing interests}

The authors declare that they have no competing interests.

\section{Funding}

The authors received no specific funding for this work.

\section{Authors' contributions}

$M D, G B, U O$ contributed to the design of the research and wrote the manuscript. $G B, A V, V C, G C, B F, F G$, $\mathrm{GBZ}, \mathrm{AC}$, UO collected, analyzed and interpreted the data concerning the cardiovascular profile of the patients. MD, VG, AB, AD, GD, EL, EM, GM, DO, GR collected, analyzed and interpreted the data regarding the diabetes. All authors read and approved the final manuscript.

\section{Acknowledgements}

Not applicable.

\section{References}

1. Ministero della Salute. Rapporto annuale sull'attività di Ricovero ospedaliero. Dati SDO 2013. 
2. Johansson I, Dahlström U, Edner M, Näsman P, Rydén L, Norhammar A. Type 2 diabetes and heart failure: Characteristics and prognosis in preserved, mid-range and reduced ventricular function. Diab Vasc Dis Res. 2018; 15:494-503.

3. Kannel WB, Hjortland M, Castelli WP. Role of diabetes in congestive heart failure: the Framingham study. Am J Cardiol 1974; 34:29-34.

4. Tarantini L, Di Lenarda A, Velussi M, Faggiano P, Comaschi M, Faglia E et al. Diabetes mellitus, left ventricular dysfunction and congestive heart failure. Ital Heart J 2004; 5: 605-615.

5. Botta A, Carbone V, Carella G, Del Buono A, De Luca M, Di Giovanni G et al. Scompenso cardiaco nel paziente con diabete in Campania (SCODIAC). The Journal of AMD 2019; 4:219-229.

6. Bosso G, Valvano A, Guarnaccia F, Fimiani B, Carbone V, Cittadini A et al. Adherence to guidelines in the management of patients with chronic heart failure follow-up: role of periodic echocardiographic examinations. J Cardiovasc Med 2020; 21:216-222.

7. Eurich DT, Weir DL, Majumdar SR, Tsuyuki RT, Johnson JA, Tjosvold L et al. Comparative safety and effectiveness of metformin in patients with diabetes mellitus and heart failure: systematic review of observational studies involving 34,000 patients. Circ Heart Fail 2013; 6:395-402.

8. Pantalone KM, Kattan MW, Yu C, Wells BJ, Arrigain S, Jain A et al. The risk of developing coronary artery disease or congestive heart failure, and overall mortality, in type 2 diabetic patients receiving rosiglitazone, pioglitazone, metformin, or sulfonylureas: a retrospective analysis. Acta Diabetol 2009; 46:145-154.

9. Tzoulaki I, Molokhia M, Curcin V, Little MP, Millett CJ, Ng A et al. Risk of cardiovascular disease and all-cause mortality among patients with type 2 diabetes prescribed oral antidiabetes drugs: retrospective cohort study using UK general practice research database. BMJ 2009; 339: b4731.

10. Dormandy JA, Charbonnel B, Eckland DJ, Erdmann E, Massi-Benedetti M, Moules IK et al. Secondary prevention of macrovascular events in patients with type 2 diabetes in the PROactive Study (PROspective pioglitazone Clinical Trial InmacroVascular Events): a randomized controlled trial. Lancet 2005; 366:1279-1289.

11. Scirica BM, Bhatt DL, Braunwald E, Steg PG, Davidson J, Hirshberg B et al. Saxagliptin and cardiovascular outcomes in patients with type 2 diabetes mellitus. N Engl J Med 2013; 369: 13171326.

12. White WB, Cannon CP, Heller SR, Nissen SE, Bergenstal RM, Bakris GL et al. Alogliptin after acute coronary syndrome in patients with type 2 diabetes. N Engl J Med 2013; 369:1327-1335.

13. Green JB, Bethel MA, Armstrong PW, Buse JB, Engel SS, Garg J et al. Effect of sitagliptin on cardiovascular outcomes in type 2 diabetes. N Engl J Med 2015; 37:232-242.

14. Fadini GP, Avogaro A, Degli Esposti L, Russo P, Saragoni S, Buda S et al. Risk of hospitalization for heart failure in patients with type 2 diabetes newly treated with DPP-4 inhibitors or other oral glucose lowering medications: a retrospective registry study on 127,555 patients from the Nationwide OsMed Health-DB Database. Eur Heart J 2015; 36:2454-2462. 
15. Margulies KB, Anstrom KJ, Hernandez AF, Redfield MM, Shah MR, Braunwald E et al. GLP-1 agonist therapy for advanced heart failure with reduced ejection fraction: design and rationale for the functional impact of GLP-1 for heart failure treatment study. Circ Heart Fail 2014; 7:673-679.

16. Marso SP, Daniels GH, Brown-Frandsen K, Kristensen P, Mann JFE, Nauck MA et al. Liraglutide and cardiovascular outcomes in type 2 diabetes. N Engl J Med 2016; 375:311-322.

17. Zinman B, Wanner C, Lachin JM, Fitchett D, Bluhmki E, Hantel S et al. EMPA-REG OUTCOME Investigators. Empagliflozin, cardiovascular outcomes, and mortality in type 2 diabetes. $\mathrm{N}$ Engl $\mathrm{J}$ Med 2015; 373:2117-2128.

18. Neal B, Perkovic V, Mahaffey KW, de Zeeuw D, Fulcher G, Erondu N et al. Canagliflozin and Cardiovascular and Renal Events in Type 2 Diabetes. N Engl J Med 2017; 377:644-657.

19. Wiviott SD, Raz I, Bonaca MP, Mosenzon O, Kato ET, Cahn A et al. Dapagliflozin and Cardiovascular Outcomes in Type 2 Diabetes. N Engl J Med 2019; 380:347-357.

20. Kato ET, Silverman MG, Mosenzon O, Zelniker TA, Cahn A, Furtado RHM et al. Effect of dapagliflozin on heart failure and mortality in type 2 diabetes mellitus. Circulation 2019; 139:2528- 253

21. Zelniker TA, Wiviott SD, Raz I, Im K, Goodrich EL, Bonaca MP et al. SGLT2 inhibitors for primary and secondary prevention of cardiovascular and renal outcomes in type 2 diabetes: a systematic review and meta-analysis of cardiovascular outcome trials. Lancet 2018; 393:31-39.

22. Kosiborod M, Cavender MA, Fu AZ, Wilding JP, Khunti K, Holl RWet al. Lower risk of heart failure and death in patients initiated on SGLT-2 inhibitors versus other glucose lowering drugs: The CVD-REAL Study. Circulation 2017; 136:249-259.

23. McMurray JJV, Solomon SD, Inzucchi SE, Køber L, Kosiborod MN, Martinez FA et al. Dapagliflozin in Patients With Heart Failure and Reduced Ejection Fraction. N Engl J Med 2019; 381:1995-2008.

24. Lan SR, Fegan PG, Yeap BB, Dwivedi G. The effects of sodium-glucose cotransporter 2 inhibitors on left ventricular function: current evidence and future directions. ESC Heart Failure, 2019; 6:927-935.

25. Sakai T, Miura S. Effect of sodium-glucose cotransporter 2 inhibitor on vascular endothelial function and diastolic function in patients with heart failure with preserved ejection fraction (HFpEF). Circulation 2018; 136: A17041

26. Soga F, Tanaka H, Tatsumi K, Mochizuki Y, Sano H, Toki H et al. Impact of dapagliflozin on left ventricular diastolic function of patients with type 2 diabetic mellitus with chronic heart failure. Cardiovasc Diabetol 2018; 17: 132

27. Guarnaccia F, Fimiani B, Zito GB, De Simone A, Stabile G, Bossone E et al. ALERT-HF: adherence to guidelines in the treatment of patients with chronic heart failure. J Cardiovasc Med 2014; 15:491497.

28. Cosentino F, Grant PJ, Aboyans V, Bailey CJ, Ceriello A, Delgado V et al. ESC Guidelines on diabetes, pre-diabetes, and cardiovascular diseases developed in collaboration with the EASD European Heart Journal, 2019. European Heart Journal 2020; 41: 255-323.

\section{Tables}


Table 1 - Clinical characteristics and laboratory data of the study population, of the HF-pEF patients (Group A) and of the HF-rEF patients (Group B)

\begin{tabular}{|c|c|c|c|c|}
\hline & $\begin{array}{c}\text { Study population } \\
n=406\end{array}$ & $\begin{array}{c}\text { Group A (EF>45\%) } \\
n=136\end{array}$ & $\begin{array}{c}\text { Group B (EF } \leq 45 \%) \\
n=270\end{array}$ & $\mathrm{P*}$ \\
\hline Women $n, \%$ & $179(44 \%)$ & $73(54 \%)$ & $106(39 \%)$ & NS \\
\hline Age $y r s$ & $73 \pm 7$ & $76 \pm 6$ & $72 \pm 7$ & NS \\
\hline $\mathrm{BMI} \mathrm{kg} / \mathrm{m}^{2}$ & $30 \pm 6$ & $32 \pm 5$ & $29 \pm 4$ & NS \\
\hline SBP $m m H g$ & $130 \pm 18$ & $135 \pm 16$ & $128 \pm 15$ & NS \\
\hline DBP $m m H g$ & $79 \pm 11$ & $83 \pm 5$ & $74 \pm 9$ & NS \\
\hline T2DM duration yrs & $15 \pm 9$ & $17 \pm 10$ & $13 \pm 7$ & NS \\
\hline $\mathrm{HbA1}$ c $\mathrm{mmol} / \mathrm{L}$ & $57 \pm 5$ & $64 \pm 3$ & $55 \pm 4$ & NS \\
\hline CHF duration $m o$ & $30 \pm 6$ & $17 \pm 5^{\star}$ & $37 \pm 7 *$ & $<0.05$ \\
\hline BNP $p m o l / m l$ & $616 \pm 354$ & $330 \pm 89 *$ & $778 \pm 153 *$ & $<0.05$ \\
\hline Total Cholesterol $\mathrm{mg} / \mathrm{dL}$ & $157 \pm 51$ & $163 \pm 54$ & $156 \pm 50$ & NS \\
\hline LDL-C $m g / d L$ & $81 \pm 30$ & $85 \pm 28$ & $79 \pm 26$ & NS \\
\hline HDL-C $m g / d L$ & $40 \pm 10$ & $43 \pm 7$ & $38 \pm 8$ & NS \\
\hline Triglycerides $m g / d L$ & $160 \pm 59$ & $147 \pm 44$ & $168 \pm 66$ & NS \\
\hline Creatinine $m g / d L$ & $1.4 \pm 0.4$ & $1.4 \pm 0.3$ & $1.5 \pm 0.3$ & NS \\
\hline Number of visits $n$ & $4 \pm 3$ & $5 \pm 3$ & $7 \pm 2$ & NS \\
\hline
\end{tabular}

*Comparison between Group A and Group B

BMI: Body Mass Index; SBP: Systolic Blood Pressure; DBP: Diastolic Blood Pressure; CHF: Chronic Heart Failure; BNP: Brain Natriuretic Peptide; LDLC: Low Density Lipoprotein Cholesterol; HDL-C: High Density Lipoprotein Cholesterol.

Table 2 -Etiologies, comorbidities and complications of the HF patients, of the HF-pEF patients (Group A) and of the HF-rEF patients (Group B) 
Study population $\mathrm{n}=406 \quad$ Group $\mathrm{A}(\mathrm{EF}>45 \%) \quad$ Group $\mathrm{B}(\mathrm{EF} \leq 45 \%) \quad \mathrm{P}^{*}$

$n=136$

$\mathrm{n}=270$

Heart Failure etiologies

\begin{tabular}{lcccc}
\hline Ischemic $n(\%)$ & $248(61 \%)$ & $47(35 \%)^{\star}$ & $201(74 \%)^{\star}$ & $<0.05$ \\
Hypertensive $n(\%)$ & $125(31 \%)$ & $79(58 \%)^{*}$ & $46(17 \%)^{\star}$ & $<0.05$ \\
Idiopathic $n(\%)$ & $33(8 \%)$ & $10(7 \%)$ & $25(9 \%)$ & NS \\
\hline
\end{tabular}

Comorbidities and complications

\begin{tabular}{|c|c|c|c|c|}
\hline Hypertension $n(\%)$ & $259(64 \%)$ & $106(78 \%)^{\star}$ & $153(57 \%)^{*}$ & $=0.05$ \\
\hline Stroke $n(\%)$ & $35(9 \%)$ & $10(7 \%)$ & $25(9 \%)$ & NS \\
\hline CAD $n(\%)$ & $268(66 \%)$ & $67(49 \%) *$ & $201(74 \%) *$ & $<0.05$ \\
\hline CABG $n(\%)$ & $60(15 \%)$ & $17(12,5 \%)$ & $43(16 \%)$ & NS \\
\hline PTCA $n(\%)$ & $142(35 \%)$ & $32(24 \%)$ & $110(40 \%)$ & NS \\
\hline Atrial Fibrillation $n(\%)$ & $62(15 \%)$ & $22(16 \%)$ & $40(15 \%)$ & NS \\
\hline Diabetic Nephropathy $n(\%)$ & $178(44 \%)$ & $55(40 \%)$ & $123(45.5 \%)$ & NS \\
\hline PAD $n(\%)$ & $98(24 \%)$ & $23(17 \%)$ & $75(28 \%)$ & NS \\
\hline Bypass for PAD $n(\%)$ & $20(5 \%)$ & $6(4 \%)$ & $14(5 \%)$ & NS \\
\hline PTA for PAD $n(\%)$ & $29(7 \%)$ & $9(7 \%)$ & $20(7 \%)$ & NS \\
\hline Diabetic Retinophathy $n(\%)$ & $69(17 \%)$ & $24(18 \%)$ & $45(17 \%)$ & NS \\
\hline Diabetic Foot $n(\%)$ & $32(8 \%)$ & $11(8 \%)$ & $21(8 \%)$ & NS \\
\hline
\end{tabular}

Data are expressed as frequencies and percentages. *Comparison between Group A and Group

B

CAD: Coronary Artery Disease; CABG: Coronary Artery Bypass

Graft; PTCA: Percutaneous Transluminal Coronary Angioplasty; PTA: Percutaneous Transluminal Angioplasty; PAD: Peripheral Atherosclerotic Disease.

Table 3 - Clinical characteristics and laboratory data of the study population, of the HF-pEF patients (Group A) and of the HF-rEF patients (Group B) at the beginning and at the end of the study 


\begin{tabular}{|c|c|c|c|c|c|c|c|c|c|}
\hline & \multicolumn{3}{|c|}{$\begin{array}{l}\text { Study population } \\
\qquad n=406\end{array}$} & \multicolumn{3}{|c|}{$\begin{array}{c}\text { Group A (EF>45\%) } \\
n=136\end{array}$} & \multicolumn{3}{|c|}{$\begin{array}{c}\text { Group B (EF } \leq 45 \%) \\
n=270\end{array}$} \\
\hline & Beginning & End & $\mathrm{P}$ & Beginning & End & $\mathrm{P}$ & Beginning & End & $\mathrm{P}$ \\
\hline BMI $\mathrm{kg} / \mathrm{m}^{2}$ & $30 \pm 6$ & $30 \pm 7$ & NS & $32 \pm 5$ & $32 \pm 3$ & NS & $29 \pm 4$ & $28.5 \pm 5$ & NS \\
\hline SBP $m m H g$ & $130 \pm 18$ & $131 \pm 20$ & NS & $135 \pm 16$ & $137 \pm 15$ & NS & $128 \pm 15$ & $127 \pm 13$ & NS \\
\hline DBP $m m H g$ & $79 \pm 11$ & $82 \pm 12$ & NS & $83 \pm 5$ & $84 \pm 6$ & NS & $74 \pm 9$ & $75 \pm 10$ & NS \\
\hline $\mathrm{HbA1c} \mathrm{mmol} / \mathrm{L}$ & $57 \pm 5$ & $55 \pm 5$ & NS & $64 \pm 3$ & $61 \pm 4$ & NS & $55 \pm 4$ & $53 \pm 6$ & NS \\
\hline BNP $\mathrm{pmol} / \mathrm{ml}$ & $616 \pm 354$ & $612 \pm 288$ & NS & $330 \pm 89$ & $401 \pm 76$ & NS & $778 \pm 153$ & $712 \pm 223$ & NS \\
\hline $\begin{array}{l}\text { Total Cholesterol } \\
\mathrm{mg} / \mathrm{dL}\end{array}$ & $157 \pm 51$ & $146 \pm 50$ & NS & $163 \pm 54$ & $154 \pm 66$ & NS & $156 \pm 50$ & $140 \pm 54$ & NS \\
\hline LDL $m g / d L$ & $81 \pm 30$ & $85 \pm 35$ & NS & $85 \pm 28$ & $86 \pm 33$ & NS & $79 \pm 26$ & $83 \pm 34$ & NS \\
\hline HDL $m g / d L$ & $40 \pm 10$ & $43 \pm 13$ & NS & $43 \pm 7$ & $44 \pm 9$ & NS & $38 \pm 8$ & $45 \pm 8$ & NS \\
\hline $\begin{array}{l}\text { Triglycerides } \\
m g / d L\end{array}$ & $160 \pm 59$ & $157 \pm 61$ & NS & $147 \pm 44$ & $144 \pm 42$ & NS & $168 \pm 66$ & $167 \pm 71$ & NS \\
\hline Creatinine $\mathrm{mg} / \mathrm{dL}$ & $1.4 \pm 0.4$ & $1.5 \pm 0.4$ & NS & $1.4 \pm 0.3$ & $1.4 \pm 0.3$ & NS & $1.5 \pm 0.3$ & $1.5 \pm 0.5$ & NS \\
\hline
\end{tabular}

BMI: Body Mass Index; SBP: Systolic Blood Pressure; DBP: Diastolic Blood Pressure; BNP: Brain Natriuretic Peptide; LDL-C: Low Density Lipoprotein Cholesterol; HDL-C: High Density Lipoprotein Cholesterol.

le 4 - Echocardiographic parameters in 136 HF-pEF patients at beginning of the study, and in 111 and 25 JEF patients without (SGLT2i-) and with (SGLT2i+) SGLT2i treatment at the end of the study. 


\begin{tabular}{|c|c|c|c|c|c|}
\hline & $\begin{array}{l}\text { Diabetic HF-pEF pts at } \\
\text { beginning of the } \\
\text { study } \quad(n=136)\end{array}$ & $\begin{array}{c}\text { Diabetic HF-pEF } \\
\text { SGLT2i-pts after } 12 \\
\text { months }(n=111)\end{array}$ & $\mathrm{p}^{*}$ & $\begin{array}{c}\text { Diabetic HF-pEF } \\
\text { SGLT2i+ pts after } 12 \\
\text { months }(n=25)\end{array}$ & $p^{* *}$ \\
\hline $\begin{array}{l}\text { ection } \\
\text { action }\end{array}$ & $52.7 \pm 2.7$ & $50.3 \pm 3.1$ & ns & $51.3 \pm 3.2$ & ns \\
\hline $\begin{array}{l}\text { I-EDV } \\
1 / \mathrm{m}^{2}\end{array}$ & $71.4 \pm 5.8$ & $72.6 \pm 4.2$ & ns & $74.6 \pm 4.2$ & ns \\
\hline $\begin{array}{l}\text { I-ESV } \\
1 / m^{2}\end{array}$ & $31.8 \pm 7.3$ & $36.2 \pm 8.4$ & ns & $33.2 \pm 8.4$ & ns \\
\hline $\begin{array}{l}\text { I- } \\
\text { ass } \\
/ \mathrm{m}^{2}\end{array}$ & $88.4 \pm 13.9$ & $85.3 \pm 15.4$ & ns & $86.4 \pm 13.9$ & ns \\
\hline $\begin{array}{l}\mathbf{l} \mathbf{V i} \\
\mathrm{t} / \mathrm{m}^{2}\end{array}$ & $37.1 \pm 4.8$ & $36.2 \pm 3.4$ & ns & $32.3 \pm 3.2$ & $<0.05$ \\
\hline $\begin{array}{l}\text { locity } \\
\text { /s }\end{array}$ & $98.6 \pm 4.2$ & $96.5 \pm 3.8$ & ns & $92.4 \pm 3.1$ & $<0.01$ \\
\hline $\begin{array}{l}\text { locity } \\
\text { /s }\end{array}$ & $118.3 \pm 6.5$ & $109.5 \pm 5.4$ & ns & $108.1 \pm 6.8$ & $<0.01$ \\
\hline $\begin{array}{l}\text { A } \\
\text { tio }\end{array}$ & $0.83 \pm 0.12$ & $0.88 \pm 0.12$ & ns & $0.85 \pm 0.16$ & ns \\
\hline $\begin{array}{l}\text { locity } \\
\text { /s }\end{array}$ & $5.7 \pm 2.3$ & $5.8 \pm 3.1$ & ns & $7.2 \pm 1.8$ & $<0.01$ \\
\hline 'E'ratio & $17.1 \pm 3.5$ & $16.7 \pm 2.5$ & ns & $12.8 \pm 2.3$ & $<0.001$ \\
\hline
\end{tabular}


Data are expressed as media \pm standard deviation; HF-pEF: Heart Failure with Preserved Ejection Fraction; LV: Left Ventricle; LAVi: Left Atrial Volume indexed for body surface area; TDI: Tissue Doppler Imaging.

* comparison between Diabetic HF-pEF pts at beginning of the study and SGLT2i- pts after 12 months

** comparison between Diabetic HF-pEF pts at beginning of the study and SGLT2i+ pts after 12 months and between Diabetic HF-pEF SGLT2i- pts and SGLT2i+ pts after 12 months

le 5 - Echocardiographic parameters in $270 \mathrm{HF}-\mathrm{rEF}$ patients at beginning of the study, and in 210 and 60 EF patients without (SGLT2i-) and with (SGLT2i+) SGLT2i treatment at the end of the study. 


\begin{tabular}{|c|c|c|c|c|c|}
\hline & $\begin{array}{l}\text { Diabetic HF-rEF pts at } \\
\text { beginning of the } \\
\text { study } \quad(n=270)\end{array}$ & $\begin{array}{c}\text { Diabetic HF-rEF } \\
\text { SGLT2i- pts after } 12 \\
\text { months }(n=210)\end{array}$ & $p^{*}$ & $\begin{array}{c}\text { Diabetic HF-rEF } \\
\text { SGLT2i+ pts after } 12 \\
\text { months }(n=60)\end{array}$ & $p * *$ \\
\hline $\begin{array}{l}\text { ection } \\
\text { action }\end{array}$ & $32.1 \pm 2.1$ & $34.2 \pm 3.2$ & ns & $37.5 \pm 3.8$ & $<0.01$ \\
\hline $\begin{array}{l}\text { I-EDV } \\
1 / \mathrm{m}^{2}\end{array}$ & $112 \pm 6.4$ & $105 \pm 7.4$ & ns & $99.5 \pm 6.3$ & $<0.5$ \\
\hline $\begin{array}{l}\text { I-ESV } \\
I / m^{2}\end{array}$ & $76 \pm 11.4$ & $73 \pm 7.6$ & ns & $64 \pm 6.5$ & $<0.01$ \\
\hline $\begin{array}{l}\text { I- } \\
\text { ass } \\
/ \mathrm{m}^{2}\end{array}$ & $97.4 \pm 16.1$ & $94.4 \pm 15.7$ & $\mathrm{~ns}$ & $92.3 \pm 13.8$ & ns \\
\hline $\begin{array}{l}\mathbf{l} \mathbf{V i} \\
\mathrm{l} / \mathrm{m}^{2}\end{array}$ & $41.3 \pm 6.2$ & $40.4 \pm 4.2$ & ns & $38.9 \pm 5.1$ & ns \\
\hline $\begin{array}{l}\text { locity } \\
\text { /s }\end{array}$ & $86.1 \pm 3.9$ & $70.4 \pm 4.1$ & $\mathrm{~ns}$ & $64.2 \pm 3.3$ & 0.05 \\
\hline $\begin{array}{l}\text { locity } \\
\text { /s }\end{array}$ & $94.2 \pm 6.5$ & $82 \pm 5.5$ & ns & $71 \pm 5.8$ & 0.05 \\
\hline $\begin{array}{l}\text { A } \\
\text { tio }\end{array}$ & $0.8 \pm 0.08$ & $0.85 \pm 0.12$ & ns & $0.9 \pm 0.13$ & 0.05 \\
\hline $\begin{array}{l}\text { locity } \\
\text { /s }\end{array}$ & $5.1 \pm 2.1$ & $4.9 \pm 2.1$ & ns & $7.1 \pm 2.4$ & $\begin{array}{r}< \\
0.01\end{array}$ \\
\hline 'ératio & $16.8 \pm 3.1$ & $14.3 \pm 2.1$ & ns & $10.3 \pm 3.3$ & $\begin{array}{r}< \\
0.001\end{array}$ \\
\hline
\end{tabular}


Data are expressed as media \pm standard deviation; HF-rEF: Heart Failure with Reduced Ejection Fraction; LV: Left Ventricle; LAVi: Left Atrial Volume indexed for body surface area; TDI: Tissue Doppler Imaging.

* comparison between Diabetic HF-rEF pts at beginning of the study and SGLT2i- pts after 12 months

** comparison between Diabetic HF-rEF pts at beginning of the study and SGLT2i+ pts after 12 months and between Diabetic HF-rEF SGLT2i-pts and SGLT2i+ pts after 12 months

\section{Figures}
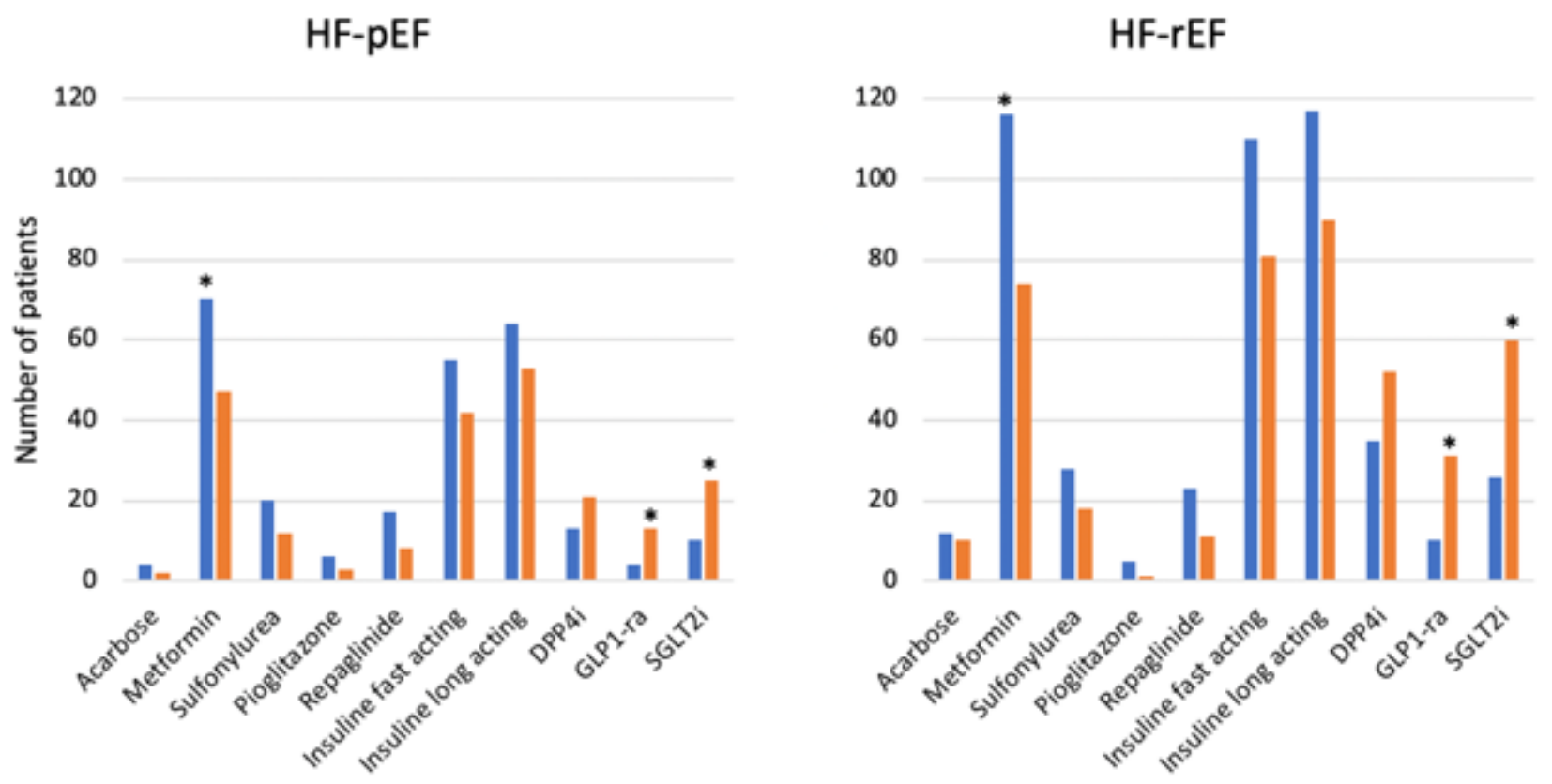

= Beginning of the study

End of the study

\section{Figure 1}

Antidiabetic Therapies of 136 HF-pEF patients (Group A) and 270 HF-rEF patients (Group B) at beginning and after 12 months. HF-pEF: Heart Failure with preserved Ejection Fraction; HF-rEF: Heart Failure with reduced Ejection Fraction; DPP4i: Dipeptidyl peptidase-4 inhibitors; GLP1-ra: Glucagon-like Peptide-1 receptor agonists; SGLT2i: Sodium-Glucose Co-Transporter 2 inhibitors. *P value $<0.05$ 

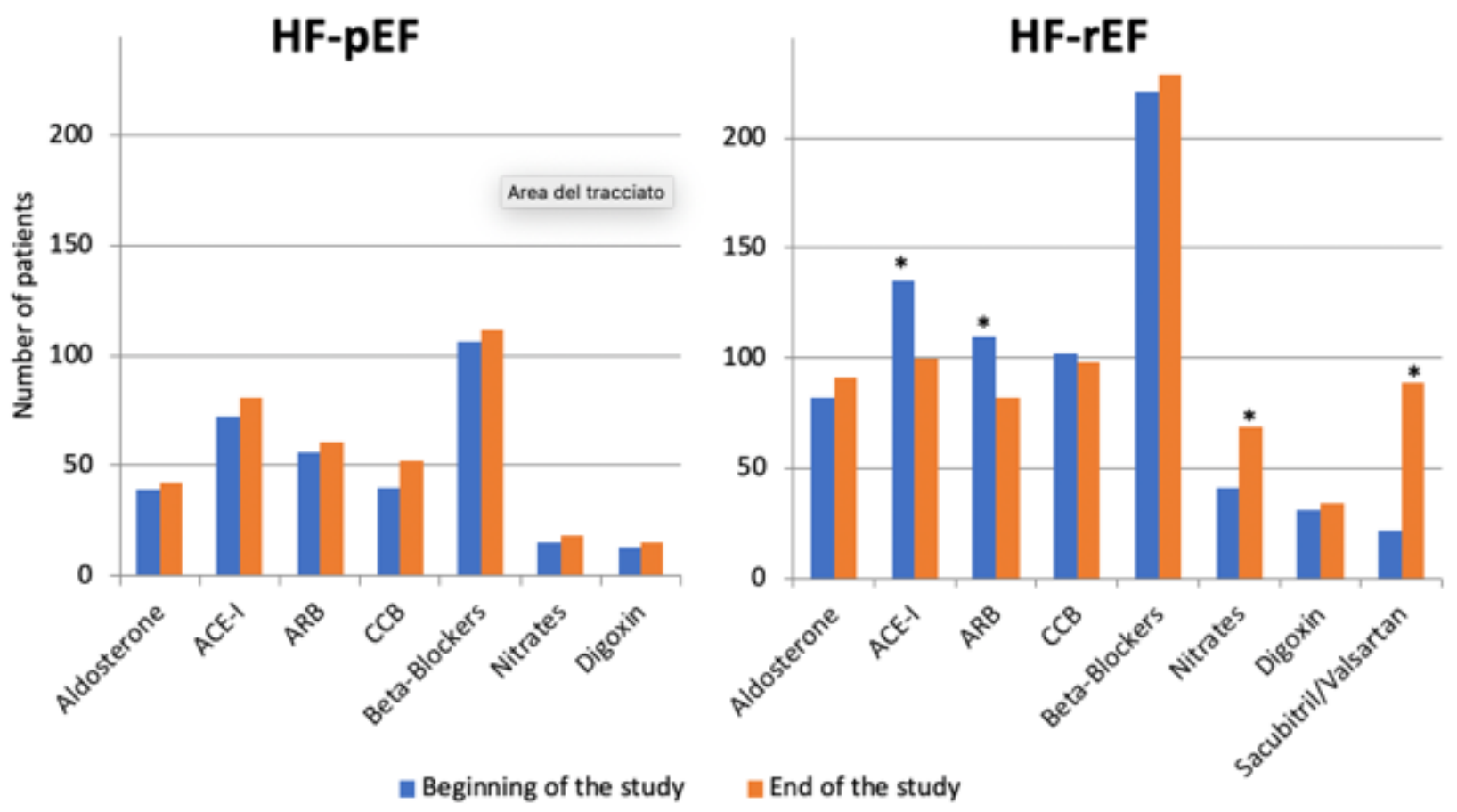

Figure 2

Cardiological Therapies of 136 HF-pEF (Group A) and 270 HF-rEF (Group B) patients at beginning and after 12 months. HF-pEF: Heart Failure with preserved Ejection Fraction; HF-rEF: Heart Failure with reduced Ejection Fraction; ACE-l: Angiotensin-converting enzyme inhibitors; ARB: Angiotensin Receptor Blockers; CCB: Calcium Channel Blockers * $\mathrm{P}$ value $<0.05$ 